\title{
Macroplastic and microplastic contamination assessment of a tropical river (Saigon River, Vietnam) transversed by a developing megacity
}

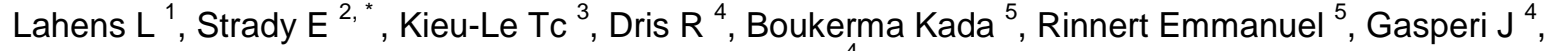 \\ Tassin $\mathrm{B}^{4}$
}

${ }^{1}$ Université Paris-Est, LEESU, UMR MA 102 - AgroParisTech, 61 Avenue du Général de Gaulle, 94010, Créteil Cedex, France

2 Univ. Grenoble Alpes, CNRS, IRD, Grenoble INP, IGE, F-38000, Grenoble, France

${ }^{3}$ CARE, Ho Chi Minh City University of Technology, VNU-HCM, Viet Nam; Faculty of Geology and

Petroleum Engineering, Ho Chi Minh City University of Technology, VNU-HCM, Viet Nam.

${ }^{4}$ Université Paris-Est, LEESU, UMR MA 102 - AgroParisTech, 61 Avenue du Général de Gaulle, 94010, Créteil Cedex, France

${ }^{5}$ Ifremer, LDCM, Centre Bretagne, ZI de la Pointe du Diable, CS 10070, 29280, Plouzané, France.

*Corresponding author : Emilie Strady, email address : emilie.strady@ird.fr

\begin{abstract}
:
Both macroplastic and microplastic contamination levels were assessed for the first time in a tropical river estuary system, i.e. the Saigon River, that traverses a developing South East Asian megacity, i.e. Ho Chi Minh City, Vietnam. The analysis of floating debris collected daily on the Nhieu Loc - Thi Nghe canal by the municipal waste management service shows that the plastic mass percentage represents $11-43 \%$, and the land-based plastic debris entering the river was estimated from 0.96 to $19.91 \mathrm{~g}$ inhabitant-1 d-1, namely 350 to $7270 \mathrm{~g}$ inhabitant-1 yr-1. Microplastics were assessed in the Saigon River and in four urban canals by sampling bulk water for anthropogenic fiber analysis and $300 \mu \mathrm{m}$ mesh size plankton net exposition for fragment analysis. Fibers and fragments are highly concentrated in this system, respectively 172,000 to 519,000 items m-3 and 10 to 223 items m-3. They were found in various colors and shapes with smallest size and surface classes being predominant. The macroplastics and fragments were mainly made of polyethylene and polypropylene while the anthropogenic fibers were mainly made of polyester. The relation between macroplastic and microplastic concentrations, waste management, population density and water treatment are further discussed.
\end{abstract}




\section{Graphical abstract}

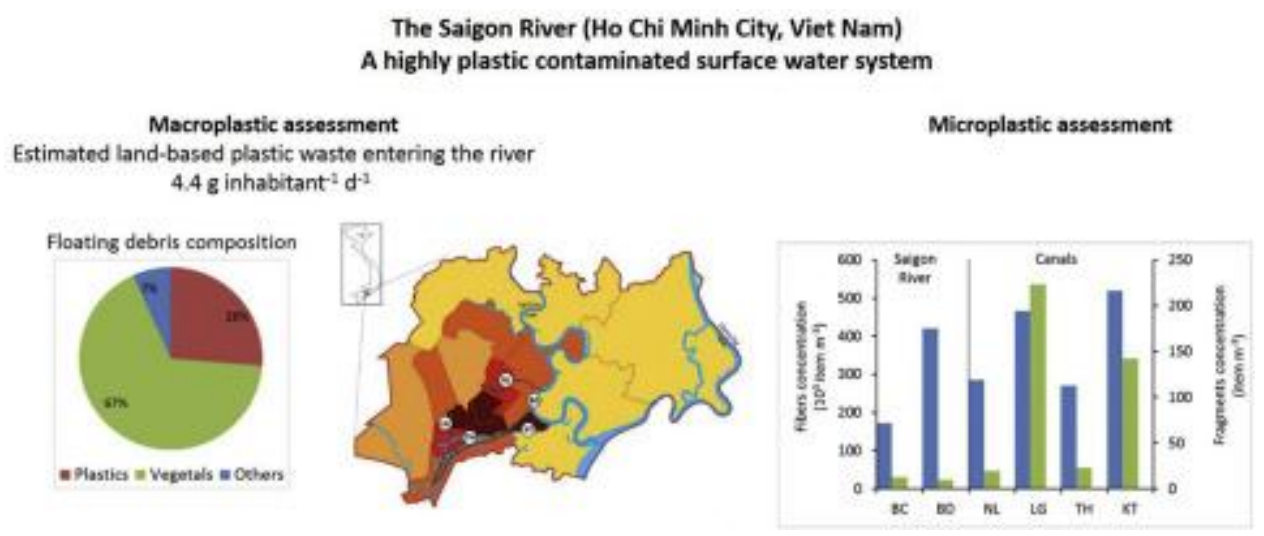

Highlights

Both macro and microplastic assessments were made in a tropical river canal system. About $4.4 \mathrm{~g}$ inhabitant ${ }^{-1} \mathrm{~d}^{-1}$ land-based plastic waste entering the river was estimated. High microplastic concentrations were found for both fibers and fragments. Characterization was carried out for macroplastics and microplastic.

Keywords : Anthropogenic fibers, Contamination, Macroplastic, Microplastic, Urban river 


\section{Introduction}

Plastics are polymers designed to be lightweight, resistant, and durable (Thompson et al., 2009). Their numerous advantages have led to a considerable increase in their production in the past 60 years: 1.7 million metric tons produced in 1950 compared with 335 million metric tons in 2017 worldwide (PlasticsEurope, 2018). However, plastic products are often mismanaged or abandoned in illegal dumping sites (Barnes et al., 2009), which can lead to environmental pollution. Their persistence in the environment makes them a good proxy of the Anthropocene's exponential consumption (Steffen et al., 2007).

Plastics are estimated to represent between 50 and $80 \%$ of marine litter (Barnes et al., 2009). Some chemicals are used as additives (e.g. alkylphenols, phthalates, bisphenol A, organophosphates, PBDEs) during plastic production to give it particular properties (durability, resistance, flexibility, reduced weight, ignition inhibition). On the one hand, plastics have the capacity to adsorb persistent organic pollutants (POP) (Bakir et al., 2012, 2014) as well as trace metals (Mato et al., 2001; Turner and Holmes, 2015) once they enter water bodies. On the other hand, animals can become entangled in large items, or smaller plastic particles can be ingested by fish and other organisms (Peters and Bratton, 2016; Sanchez et al., 2014; Silva-Cavalcanti et al., 2017) and once they are ingested, they can clog the digestive system or release adsorbed hazardous chemicals that could harm the biota (Bejgarn et al., 2015).

There has been increased interest since plastic was first assessed in the marine aquatic environment in 1972 (Carpenter and Smith, 1972) and has been expanding to the continental aquatic environment for the past few years (Dris et al., 2015a; Eerkes-Medrano et al., 2015; Horton et al., 2017; Wagner et al., 2014). Plastic debris is generally assessed according to size: macroplastics, i.e. plastic items superior to $5 \mathrm{~mm}$, and microplastics, i.e. plastic items inferior to $5 \mathrm{~mm}$ (Arthur et al., 2009; Barnes et al., 2009; Thompson et al., 2009). More precisely, 
microplastics can be classified as (i) primary microplastics that are specifically engineered to be used in this form, mainly in cosmetic products or as preproduction pellets, and as (ii) secondary microplastics that come from the degradation of larger plastic items mainly due to photo-degradation or mechanical action (Cooper and Corcoran, 2010; Derraik, 2002; Napper et al., 2015; Williams and Simmons, 1996). In the continental aquatic environment, microplastic assessment is conducted to estimate contamination of the environment and influence of anthropogenic activities (e.g. Faure et al., 2015; Mani et al., 2015; Zhang et al., 2015), and also to evaluate microplastic ingestion and impact on organisms (e.g. Jabeen et al., 2017; Jemec et al., 2016; Rehse et al., 2016).

With regards to macroplastic, it is widely considered that around $80 \%$ of marine debris is from land-based sources (Allsopp et al., 2006), even though a recent study estimated that $30 \%$ of coastal plastic debris comes from marine activities and $47 \%$ corresponds to unidentifiable fragments (Expéditions MED, 2016). Therefore, the macroplastic assessments from in situ sampling aim to both quantify the floating debris (Morritt et al., 2014) and estimate the riverine plastic fluxes or plastic exported to oceans (Estahbanati and Fahrenfeld, 2016; Gasperi et al., 2014). The mass estimate of continental plastic waste entering the ocean can also be calculated using a statistical approach based on governmental databases as exposed by Jambeck et al. (2015). Indeed, the mass of mismanaged plastic waste generated by populations living within $50 \mathrm{~km}$ of the coast and the mass of plastic marine debris potentially entering the ocean were estimated for each country. Over the ten top ranked countries, eight originate from Asia and five are considered as lower middle-income countries by the World Bank: Indonesia, Philippines, Vietnam, Sri Lanka and Bangladesh (Jambeck et al., 2015). It is important to note that microplastic and macroplastic assessments are scarce in these lower middle-income countries (Rochman et al., 2015) and that most studies are conducted in high-income countries (e.g. Chae and An, 2017; Dris et al., 2015a; Eerkes-Medrano et al., 2015; Horton et al., 2017; 
Wagner et al., 2014). Furthermore, Asia is one of the least studied continents in term of microplastic contamination, which is contradictory with recent estimations showing that Asian rivers introduce most of the worldwide continental plastic into the oceans (Lebreton et al., 2017).

Ho Chi Minh City (HCMC) is the economic capital of Vietnam and is one of the most dynamic developing megacities of South-East Asia. The increasing population (over 8 million inhabitants, 3\% growth per year; Kieu-Le et al., 2016) and its economic and industrial development (7\% of gross regional domestic product in the beginning of 2017, VGP News, 2017) have tremendous consequences on the quality of its aquatic environment, especially on the Saigon River estuary system and its canals which intersect the city (Le et al., 2016; Strady et al., 2017). Most of the city's wastewaters are discharged directly into the Saigon River and its canals because only $10 \%$ of the total produced municipal wastewater is treated with activated sludge (FAO, 2014). The major floating macroplastic contamination observed in the canals for the last two decades (Givental, 2014) has led HCMC's environmental public institution to reinforce the floating debris collection in the biggest canals. Between 2,000 to 13,000 metric tons of floating debris are collected annually on the main urban canals (Kieu-Le et al., 2016). Plastic waste mismanagement in Vietnam ( $4^{\text {th }}$ world ranked according to Jambeck et al., 2015) is a critical issue which has important environmental consequences. In this context, we selected the Saigon River system to implement the first assessment of both macroplastic and microplastic contamination in a tropical, urban river estuary system intersecting a South East Asian megacity, HCMC, in the lower middle-income country Vietnam. The aims of the study were (i) to evaluate the rate and type of macroplastics in the canal floating debris, (ii) to estimate the land-based plastic debris entering the river per inhabitant, (iii) to assess the microplastic (anthropogenic fibers and fragments) contamination levels in the canals and Saigon River surface waters, and (iv) to compare the results to studies conducted in high-income countries. 
For this comparison, we focus on the megacity of Paris crossed by the Seine River as a similar methodology is used for both micro and macro plastics in each study (Dris et al., 2015b; Gasperi et al., 2014).

\section{Materials and methods}

\subsection{Study area}

The Saigon River is located in Southern Vietnam and is about $250 \mathrm{~km}$ long with a catchment area of $4,717 \mathrm{~km}^{2}$. It originates in southeastern Cambodia, flows through the economic capital city of HCMC where the river is connected to a dense urban canal network (700 km length), confluences with the Dong Nai River (470 km long), and then flows into the Can Gio mangrove and South China Sea (Figure 1). The Saigon River is in a tropical monsoon climate (one rainy and one dry season) and is affected by asymmetric semi-diurnal tides. Despite a tidal range up to 3 meters, the resulting water discharge over a tidal cycle is low and present a mean annual flow rate of $85 \mathrm{~m}^{3} \mathrm{~s}^{-1}$ (Nguyen et al., 2011). The canal network dynamic is partly controlled by floodgates and has low current velocity. The canal water quality is poor (e.g. Strady et al., 2017) and has been deteriorating for the past four decades due to natural and socioeconomic factors, including flood sediment deposition and maintenance neglect (Givental, 2014). The river catchment basin drains most of the untreated wastewater from dense urban districts (up to 40,000 people $\mathrm{km}^{-2}, 2014$, HCMC Statistical Office) and industrial zones (17 zones), which include textile, apparel, plastic and packaging production industries.

This study focusses on the Saigon River and four of its main canals (Figure 1). The macroplastic assessment was conducted on the Nhieu Loc - Thi Nghe (NL) canal. We note that the floating debris of this canal is collected daily by a municipal company (Kieu-Le et al., 2016). The microplastic assessment was conducted on the Saigon River at Ben Cui (BC), $85 \mathrm{~km}$ upstream HCMC, and at Bach Dang (BD), in the city center, and on the four main urban canals: Nhieu 
Loc - Thi Nghe (NL), Tau Hu (TH), Kenh Te (KT) and Lo Gom (LG).

\subsection{Macroplastic assessment}

\section{Sampling}

Five representative sub-samples ( 3 to $5 \mathrm{~kg}$ each; $21 \mathrm{~kg}$ total) of floating debris were collected on the NL canal in April 2016 (two campaigns). The floating debris collection (from water surface to up down to $70 \mathrm{~cm}$ depth), under the supervision of a public company since 2012, aims mainly at improving the cleanness of the surface water for esthetic and population perception purpose. Workers collect the floating debris manually from boats using nets $(2 \mathrm{~cm}$ mesh size) towed on each side of the boat and also by using landing nets when floating debris is less accessible (Supporting Information Figure S1; Kieu-Le et al., 2016). We note that as the mesh size is of $2 \mathrm{~cm}$, the fraction of macroplastics between $5 \mathrm{~mm}$ and $2 \mathrm{~cm}$ is discarded and not taken into account in the total mass calculation. The floating debris sub-samples were separated in the laboratory into the following categories: vegetation, plastics and others. The plastics were visually sorted into three groups: plastic bags, food packaging and other plastics. Finally, each category and sub-category were weighed and the wet mass percentage of each was estimated. The results are expressed in wet weight in order to be compatible with figures provided by the company's database. A panel of plastics (41 plastic bags, 2 plastic cups, 2 straws and 2 plastic spoons) was characterized by Fourier Transform InfraRed spectroscopy coupled to an Attenuated Total Reflectance accessory (FTIR-ATR, UPEC, Créteil, France) using a database containing spectra references of the most common polymers.

\section{Land-based plastic release estimation calculation}

A rough estimation (minimum and maximum value) of land-based plastic waste weight entering the river was calculated (in $g$ inhabitant ${ }^{-1} \mathrm{~d}^{-1}$ and $\mathrm{g}$ inhabitant ${ }^{-1} \mathrm{yr}^{-1}$ ) according to a set of four assumptions. The first assumption is about the daily collected floating debris weight which fluctuates daily between 10 and 12 metric tons $\mathrm{d}^{-1}$ in accordance with the daily floating 
debris collection weight database of the public collection company (Kieu-Le et al., 2016). The second assumption refers to the percentage of floating debris captured by the collection team. Although the floating debris collection on this canal seems to be visually very thorough, the collection recovery efficiency is not quantified and varies daily according to the amount of floating debris and the effectiveness of the worker. Accordingly, we estimated that the capture efficiency varies between two extreme situations: an effective collection representing a $100 \%$ recovery and a poor collection representing $50 \%$ recovery of the debris floating in the canal. The third assumption relies on the percentage of plastic debris in the collected floating debris. This percentage is estimated from the minimum, maximum and mean plastic percentage weighed in the collected floating debris. The fourth assumption concerns the inhabitant population estimations in the canal basin, which vary from 522,000 inhabitants (Thao and Godfrey, 2014) to 1.2 million inhabitants (World Bank, 2012) depending on statistical sources. We note here that as the floating debris are collected daily, we consider that the residence time of the floating debris in the surface water is short enough to be excluded from the rough estimation of land-based plastic waste weight entering the river.

\subsection{Microplastic assessment}

\section{Sampling}

Microplastics, composed of fragments and anthropogenic fibers, were sampled at two sites of the Saigon River and on the four main canals during both rainy (December 2015) and dry (April 2016) seasons from separate sampling. Contrary to previous study using an $80 \mu \mathrm{m}$ mesh size net to collect fibers (Dris et al 2015b), the high fibers contents measured in the river water during a preliminary survey enabled us to consider a raw water sample for fibers analysis. Thus at each sampling site, a sample of $300 \mathrm{~mL}$ bulk water was collected using a bucket for fiber analysis. As commonly done in the literature (e.g. Eerkes-Medrano et al., 2015, Dris et al., 2015a) fragments were collected using a $300 \mu \mathrm{m}$ mesh size net exposed in surface water for 
60 seconds, combined with a General Oceanic ${ }^{\circledR}$ flowmeter to determine the sampled water volume. The net was then rinsed from the outside and the collected fraction was recovered in a glass container.

\section{Pre-treatment and density separation}

Both bulk and $300 \mu \mathrm{m}$ fraction samples were treated based on a previous version of the protocol of Mintenig et al. (2014). At first, $1 \mathrm{~g}$ of Sodium Dodecyl Sulfate (SDS, Merck ${ }^{\circledR}$ ) was added to the sample and kept in a closed bottle at $70^{\circ} \mathrm{C}$ for $24 \mathrm{~h}$ in a laboratory oven. Then 1 $\mathrm{mL}$ of biozym SE (protease and amylase, Spinnrad ${ }^{\circledR}$ ) and $1 \mathrm{~mL}$ of biozym $\mathrm{F}$ (lipase, Spinnrad $\left.{ }^{\circledR}\right)$ were added to the sample and kept at $40^{\circ} \mathrm{C}$ for $48 \mathrm{~h}$, before adding $15 \mathrm{~mL}$ of hydrogen peroxide $\left(\mathrm{H}_{2} \mathrm{O}_{2}\right.$, Merck $\left.{ }^{\circledR}\right)$ and kept again at $40^{\circ} \mathrm{C}$ for $48 \mathrm{~h}$ in the laboratory oven. Then, a density separation step was performed using a saturated zinc chloride solution $\left(\mathrm{ZnCl}_{2}\right.$ Merck $\left.{ }^{\circledR}, 1.6426 \pm 0.0016 \mathrm{~g} \mathrm{~cm}^{-3}\right)$. Lastly, the samples were filtered through glass fiber filters (GF/D, $2.7 \mu \mathrm{m}$ porosity) using a glassware filtration unit.

\section{Sample analysis}

The filters were observed using a Leica MZ12 stereomicroscope at a 16 to 160 -fold magnification. We note that anthropogenic fibers and fragments were counted and measured using the measuring tool of the image analysis software $\left(\right.$ Histolab $\left.^{\circledR}\right)$ with a lower length limit set at $50 \mu \mathrm{m}$ as smaller items were hard to identify. In this study, we defined as anthropogenic fibers the synthetic fibers from petrochemical origin (e.g. polyester, polyamide, polypropylene,etc), the artificial fibers from cellulose (e.g. viscose, rayon) and the natural fibers (e.g. cotton, wool) used in textile and apparel industries. These fibers are transported in the environment by water (Dris et al., 2018) and by air (Dris et al., 2016) and are ingested by macrofauna (Remy et al., 2015). Anthropogenic fibers were exclusively counted and measured (length in $\mu \mathrm{m}$ ) on filters from bulk samples. Fragments were evaluated (length and surface in $\mu \mathrm{m}$ and $\mu \mathrm{m}^{2}$ respectively) from net sample filters. The thickness of fibers and fragments was 
also measured on sub-samples by raising the particles with pliers. The composition of anthropogenic fibers and fragments were evaluated by FTIR microscopy used in reflection and transmission modes (IFREMER, Brest, France) on both fiber and fragment sub-samples: 76 fibers over a total of 725 fibers (about 10\%) and 57 fragments over a total of 368 fragments (about 15\%). The FTIR microscopy measurements were performed with a Thermo IS50 infrared spectrometer coupled to an infrared Thermo Nicolet $^{\mathrm{TM}}$ Continuum ${ }^{\mathrm{TM}}$ microscope with a 15x IR objective and a Mercury Cadmium Telluride (MCT) single element detector cooled with liquid nitrogen. The spectra resolution was $4 \mathrm{~cm}^{-1}$. For fibers, each fiber without size consideration was placed in a diamond micro-compression cell, one by one, and was flattened between the two diamond anvils of a SPECAC® micro compression cell purchased from Eurolabo (IFREMER, Brest, France). The identification of the fragment and anthropogenic fiber' nature was performed using the Thermo IR polymer database.

\section{Expression of results}

The anthropogenic fiber and fragment observations were expressed in number of particles per $\mathrm{m}^{3}$ (items $\mathrm{m}^{-3}$ ). We also estimated anthropogenic fiber and fragment particle mass concentrations $\left(\mathrm{mg} \mathrm{m}^{-3}\right)$ based on two assumptions relative to polymer density and particle volume. Concerning the estimation of polymer density, we took into account the lowest and highest densities of polymers sampled in surface freshwaters (this study; Di and Wang et al., $2017)$ in order to have a rough density estimation range: the lightest $\left(0.9 \mathrm{~g} \mathrm{~cm}^{-3}\right.$ - polypropylene PP) and the heaviest (1.6 $\mathrm{g} \mathrm{cm}^{-3}-$ polyvinyl chloride PVC). Concerning the estimation of particle volume, the individual measured length of fibers and surface of fragments were taken into account with a rough estimation of fibers diameter and fragments volume based on a minima and maxima measurements made on fibers and fragments sub-samples, respectively from a minimum of $8 \mu \mathrm{m}$ to a maximum of $20 \mu \mathrm{m}$ for fibers and a minimum of $10 \mu \mathrm{m}$ and a maximum of $40 \mu \mathrm{m}$ for fragments. 


\section{Results and discussion}

\subsection{Macroplastics}

In the Nhieu Loc - Thi Nghe (NL) canal, vegetation (e.g. water hyacinth and coconut) made $67 \%$ of the wet weight while other debris (e.g. aluminum cans, glass bottles, clothes) accounted for only $7 \%$ in mass. Plastic debris mass ranged from 12 to $43 \%$ of the total debris weight with a mean of $26 \%$ (Figure 2 .A). The sorting of plastic debris highlighted that plastic bags represented $37 \%$ of the total plastic debris mass (Figure $2 . \mathrm{B}$ ), namely $9 \%$ of the total debris mass. These bags were found in many different colors and textures. Food packaging items made of polystyrene represented 9 to $22 \%$ of the plastic mass (Figure $2 . \mathrm{B}$ ) and 2 to $7 \%$ of the total debris mass. Other plastic debris was composed of plastic bottles, drinking recipients and plastic cutlery. This category constituted nearly half the weight of the plastic debris (Figure 2.B) and around $11 \%$ of the total debris weight which is in the same range as observed in the Seine River (Gasperi et al., 2014) and the Thames River, where it amounted to around 30\% of plastic debris (Morritt et al., 2014). The qualitative screening of a panel of plastic bags, cups, straws and spoons showed that they were made of polyethylene (PE, 79\%), polypropylene (PP, 15\%) and polyethylene terephthalate (PET, 4\%) (Figure 2C). We note that one plastic bag was made of both PE and PP (Figure 2.C). These proportions are coherent with the global production of polymers (PlasticsEurope, 2016).

Considering the set of four assumptions used for the estimation of the land-based plastic release to the river (section 2.2) and the estimated minimum and maximum plastic percentages (12 and $43 \%$ ), the land-based plastic waste entering the NL canal was found to lie between 0.96 and $19.91 \mathrm{~g}_{\text {inhabitant }}^{-1} \mathrm{~d}^{-1}$ (for calculation refers to Supporting Information Table S1), namely 350 to $7,270 \mathrm{~g}$ inhabitant $^{-1} \mathrm{yr}^{-1}$. The median was calculated at $4.43 \mathrm{~g}$ inhabitant $\mathrm{t}^{-1} \mathrm{~d}^{-1}$, namely around $1,620 \mathrm{~g}$ inhabitant ${ }^{-1} \mathrm{yr}^{-1}$. This daily land-based plastic waste entering the river per inhabitant (0.96-19.91 $\mathrm{g}$ inhabitant $\left.\mathrm{t}^{-1} \mathrm{~d}^{-1}\right)$ is smaller than the plastic release into the river $(13.5-36.0 \mathrm{~g}$ 
inhabitant ${ }^{-1} \mathrm{~d}^{-1}$ ) estimated by Jambeck et al. (2015) from governmental data using conversion rates (e.g. 15 and $40 \%$ ) of calculated mismanaged plastic waste into marine debris. This difference of land-based plastic waste entering the river could be related to the difference of methodology between the two studies. In the NL canal, only the floating debris superior to 2 $\mathrm{cm}$ is collected: the debris, including macroplastics, that sink or settle on the riverbed are neglected. In the Thames River, Morritt et al. (2014) point out that a large, unseen volume of submerged plastic is flowing into the marine environment. The underestimation of this subsurface component in our study could lead to an underestimation of the floating debris and therefore to a lower estimation of plastic release per inhabitant. Secondly, the estimation of the daily land-based plastic waste entering the river per inhabitant of this study is partly based on a field campaign conducted on the main canal of the country's economic capital, whereas the release calculated by Jambeck et al. (2015) is based on a theoretical approach at the country scale. It can be easily assumed that the waste management disparity observed at the scale of two canals in HCMC by Kieu-Le et al. (2016) (i.e., technical support and constraint, human resources), would be even more pronounced at the scale of the city or the country. A great difference could be expected for instance between rural provinces and high-income provinces such as HCMC. In a high-income country, the estimated plastic release to the river per inhabitant of a similar river system, i.e. the Seine River crossing the megacity of Paris (10 million inhabitants) in France, is of $2.3 \mathrm{~g}$ inhabitant ${ }^{-1} \mathrm{yr}^{-1}$ (e.g. 1.3-8.2 $\mathrm{g}_{\text {inhabitant }} \mathrm{yr}^{-1}$, Gasperi et al., 2014), namely 700 times lower than the plastic release calculated in HCMC's canal (median: 1,620 $\mathrm{g}$ inhabitant ${ }^{-1} \mathrm{yr}^{-1}$; min-max: 350- 7,270 $\mathrm{g}$ inhabitant $\mathrm{H}^{-1} \mathrm{yr}^{-1}$ ). Based on these estimations, it appears that land-based plastic waste entering the river is directly related to waste management at the national, regional or district level. On a global scale, plastic release found in HCMC is one order of magnitude higher than world estimates of land-based plastic waste 


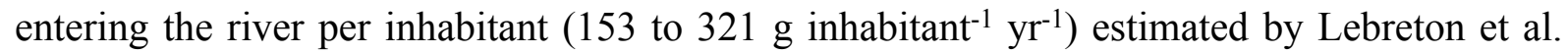
(2017) from a worldwide modeling approach.

\subsection{Microplastics}

\section{Anthropogenic fibers}

The anthropogenic fibers sampled in the four canals and in the Saigon River were found in various colors and lengths (Figure 3). The fiber size distribution of each site was similar and evidenced the predominance of small fibers $(50-250 \mu \mathrm{m})$ (Table 1), the largest size classes (> $1,000 \mu \mathrm{m}$ ) being barely represented. The cumulative number of fibers per size class sampled in the whole system (Figure 4) represents the distribution patterns observed in the Saigon River canal system. The chemical characterization of 76 anthropogenic fibers selected randomly showed (i) that $92 \%$ of the fibers were synthetic fibers, namely $70 \%$ of polyester (with $9 \%$ of polyethylene terephthalate (PET)), 5\% of polyethylene (PE) or polypropylene (PP), 4\% of PP, $4 \%$ of PE-PP copolymer, $4 \%$ of rayon, $1 \%$ of PP-vistalon, $1 \%$ of viscose and $1 \%$ of acrylic, (ii) that $5 \%$ of fibers were natural fibers namely $4 \%$ of cotton and $1 \%$ of wool and (iii) that $3 \%$ of the fibers were unidentified. Surprisingly, in comparison to other studies assessing the proportion of synthetic or anthropogenic fibers in continental aquatic environment (e.g. Dris et al., 2018), the proportion of synthetic fibers in comparison to not synthetic fibers (e.g. viscose, rayon, cotton, wool.) is extremely high. The proportion of synthetic fibers measured in the water (i.e. $92 \%$ ) is in accordance with the global fiber production market (95 million metric tons, TextileExchange, 2017) which is dominated by synthetic fibers production (65 million metric tons, TextileExchange, 2017) and especially polyester production (52 million metric tons TextileExchange, 2017). It also could reflect the possible sources of anthropogenic fibers to the aquatic environment from the textile and apparel industry in the surroundings of HCMC.

The anthropogenic fiber concentrations determined at each site ranged from 172,000 items $\mathrm{m}^{-}$ ${ }^{3}$ at $\mathrm{BC}$ to 519,000 items $\mathrm{m}^{-3}$ at KT (Figure 5), resulting in a variation of up to 3 folds between 
sites. The corresponding estimated anthropogenic fiber mass concentrations ranged from 4.72 $\mathrm{mg} \mathrm{m} \mathrm{m}^{-3}$ at $\mathrm{BD}$ considering the minimizing assumptions to $220.63 \mathrm{mg} \mathrm{m}^{-3}$ at $\mathrm{KT}$ considering the maximizing assumptions, with an overall median at $31.71 \mathrm{mg} \mathrm{m}^{-3}$ (Supporting Information Table S2). In the Saigon River, the difference of concentrations between the upstream site BC

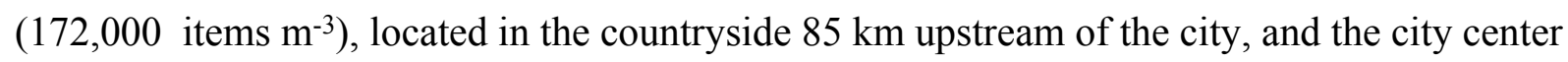

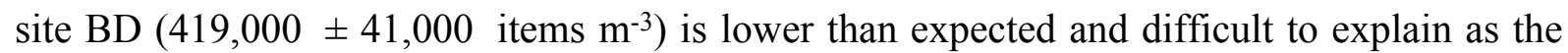
population densities between the two sites differ by more than one order of magnitude and many textile and plastic industries are located up to $20 \mathrm{~km}$ upstream BD. We note that this unexpected tendency was also observed in the Seine River between the sites located upstream and downstream of the Paris megacity (Dris et al., 2015b). The concentrations in the canals varied from 270,000 items $\mathrm{m}^{-3}$ in TH to 519,000 items $\mathrm{m}^{-3}$ in KT (Figure 5). The KT and LG canals flow through the districts with the highest population densities $\left(>40,000 \mathrm{~km}^{2}\right.$, Figure 1) with many sub-canal tributaries. The absence of wastewater treatment plants (WWTP) and of floating debris collection in this area lead respectively to a large amount of wastewater discharge and to a visible littering in these canals. The lower concentrations observed in NL and $\mathrm{TH}$ canals could be related to recent rehabilitation of these canals in terms of a drastic reduction in illegal housing along the canals and the improvement of water quality carried out by the World Bank (2012) and the Japan International Cooperation Agency improvement program (JICA, 2001), respectively.

Compared to the anthropogenic fiber concentrations in other riverine systems, the fiber concentrations measured in the Saigon River canal system are two order of magnitude higher than in the Yangtze River (1911 \pm 701 items $\mathrm{m}^{-3}$; Wang et al., 2017) and Hanjiang River (2300 \pm 250 items $\mathrm{m}^{-3}$; Wang et al., 2017) in China, three to five orders of magnitude higher than in the Seine River surface water (3-106 items $\mathrm{m}^{-3}$; Dris et al., 2015b; Dris et al., 2018) and six orders of magnitude higher than the Swiss rivers Rhône, Aubonne, Venoge and Vuachère ( 0.7 
items $\mathrm{m}^{-3}$; Faure et al., 2015). The predominance of small fibers $(50-250 \mu \mathrm{m}$; Table 1$)$ observed in the Saigon River canal system differed also from the distribution size observed in the Seine River where the $(250-450 \mu \mathrm{m})$ size is the dominant one (Dris et al., 2018). We note that despite the difference of context between these three systems, the methodology used differed: fibers were sampled in bulk water in the Saigon River, Yangtze River and in the Hanjiang River, using a $80 \mu \mathrm{m}$ mesh size net in the Seine River and a $300 \mu \mathrm{m}$ mesh size net in the Swiss rivers. We therefore conclude that the difference of sampling without net (bulk water) or with different mesh size net is important and can introduce a bias as discussed by Dris et al. (2018) in the determination of fiber concentrations and the dominant size class. Furthermore, the contamination levels are comparable to the fiber concentrations measured in raw WWTP of the Seine River basin (Dris et al., 2015b) and in influents of Dutch WWTP (Leslie et al., 2017), and are even higher than fiber concentrations measured in the final WWTP effluents discharged in the North Sea in Sweden (Magnusson and Norén, 2014), in the Baltic Sea in Finland (Talvitie et al., 2015), and from several facilities in the USA (Mason et al., 2016). However, we have to take into account for the site comparison that each study has a specific lower observation limit for counting and measuring the fibers, from 10 to $300 \mu \mathrm{m}$, leading likely to a bias in concentration estimation. Experimental studies have evidenced that washing machines can discharge up to 728,000 fibers from a $6 \mathrm{~kg}$ wash load (Napper and Thompson, 2016), which can lead to high fiber concentrations in effluent originating from washing machine discharge (Browne et al., 2011; Dris et al., 2015b; Hartline et al., 2016; Napper and Thompson, 2016). In Vietnam, the use of washing machines is less common than in high-income countries but we do not exclude that both washing machines and handwashing could be sources of fiber discharge in the canals and river. Moreover, the presence of many textile industries in HCMC (as discussed above) coupled to the quasi absence of treatment of domestic (i.e. 10\%; FAO, 2014) and industrial wastewaters (e.g. discharge into the river estimated at $200,000 \mathrm{~m}^{3} \mathrm{~d}^{-1} ;$ Vo, 
2007) are an important source of fiber contamination in the Saigon River and canal system. Thus, compared to concentrations measured worldwide in various systems, the fiber concentrations measured in the Saigon River canal system might reflect the consequences of inadequate wastewater treatment on fiber concentrations in an aquatic system.

\section{Fragments}

In the urban canals and the Saigon River, a high variety of colors and shapes of fragments (i.e. irregular and regular shapes, lines, ovals, films and foams) were observed, with a predominance of the blue color and the irregular shape (Figure 3). No microbeads were observed. Similar microplastic fragment diversity and absence of microbeads were observed in the Yangtze River (Zhang et al., 2015) and the Three Gorges Reservoir (Zhang et al., 2017) in China, while the presence of microbeads were observed in the Rhine River, Germany (Mani et al., 2015). The absence of microbeads in the Saigon River system could be explained by a difference in consumer habits or cosmetics composition between countries, as microbeads mainly originate from facial cleansers (Napper et al., 2015). The chemical characterization of 57 fragments selected randomly showed that $40.4 \%$ of the fragments were made of PE, with $19.3 \%$ of oxidized PE, $24.6 \%$ of PP, $14 \%$ of PE/PP, $3.5 \%$ of PS, $1.8 \%$ of PA, $1.8 \%$ of PVC, $1.8 \%$ of polyepoxy, $1.8 \%$ of polyester, $1.8 \%$ of PE/ethyl acrylate, while $8.8 \%$ of fragments appeared to be non-plastic (cellulose, mineral). Considering that this characterization is representative of all the fragments measured (368 fragments in total), we evaluate that the visual determination of the plastic fragments on filters has a precision of $9 \%$. The proportions of polymers are in agreement with global polymer production (PlasticsEurope, 2016) and with the characterization of macroplastics in the NL canal.

The cumulative number of fragments for all sites showed that the smallest fragment surface size class (500 to $50,000 \mu \mathrm{m}^{2}$ ) was predominant and represented half of the total number of fragments (Table 1; Figure 6). Contrary to fibers, the fragment number distribution per size 
class varied between the sampling sites (Table 1; Figure 7). The smallest surface size class was not systematically the dominant one. In $\mathrm{TH}, 70 \%$ of the fragments were in the smallest size class whereas in $\mathrm{BC}, \mathrm{BD}$, and $\mathrm{NL}$, the smallest fraction represented only $30 \%$ of fragments. In terms of maximum length of the fragments, the mean value was around $835 \mu \mathrm{m}$ and the median around $520 \mu \mathrm{m}$.

The fragment concentrations varied from 10 items $\mathrm{m}^{-3}$ in the Saigon River at BC to 223 items $\mathrm{m}^{-3}$ in the canals at LG (Figure 8). As observed for fibers, the difference of fragment concentrations is unexpectedly low between $\mathrm{BC}$ and $\mathrm{BD}$. In the canals, the highest fragment concentrations were measured in LG and KT (223 items $\mathrm{m}^{-3}$ and 142 items $\mathrm{m}^{-3}$ respectively) while they were 10 times lower in NL and TH (19 items $\mathrm{m}^{-3}$ and 23 items $\mathrm{m}^{-3}$ respectively). This pattern is similar to fiber concentrations and could have the same explanation of lower concentrations in NL and TH canals: the difference of population density and resulting inputs, the effect of the canals rehabilitation, and the presence of floating debris collection on these two canals (Kieu-Le et al., 2016) reducing macroplastic contamination and thus its degradation into microplastic fragments. We also hypothesized that the water stagnation observed in LG canal can contribute to microplastic accumulation, as observed in the Three Gorges Dam system in China (Zhang et al., 2015). However, at KT, the water is not stagnant and is largely influenced by tides. This canal is subjected to intense maritime traffic and boat habitation that could import significant amounts of fragments from wastewater discharge and littering.

The fragment concentrations comparison to high-income countries emphasizes that higher concentrations were found in the Saigon River system than in the Swiss rivers Rhône, Aubonne, Venoge and Vuachère (Faure et al., 2015) and in the Tamar Estuary in the UK (Sadri and Thompson, 2014), and the same range of concentrations was found in the Amsterdam canals in the Netherlands in bulk water samples with an observation limit of $10 \mu \mathrm{m}$ (Leslie et al., 2017). Interestingly, the fragment concentrations in the river and canals are in the same range as in the 
Yangtze, Jiaojiang, Oujiang and Minjiang estuaries in China (e.g. the first ranked country for mismanaged plastic waste and marine debris entering the ocean; Jambeck et al., 2015) despite that they have an observation limit of $500 \mu \mathrm{m}$ (Zhao et al., 2014, 2015) compared to the $50 \mu \mathrm{m}$ limit in the present study. We also note here that the estimated concentrations of fragments depend on the observation limit, i.e. a lowest limit providing a higher concentration, the smallest fractions being the most abundant (this study, Wang et al., 2017).

The fragment mass concentrations were estimated for each site from $0.01 \mathrm{mg} \mathrm{m}^{-3}$ in $\mathrm{TH}$ with the minimizing assumptions to $1.91 \mathrm{mg} \mathrm{m}^{-3}$ in LG with the maximizing assumptions, with an overall median at $0.15 \mathrm{mg} \mathrm{m}^{-3}$ (for calculation see Supporting Information Table S3). The highest concentrations were found in KT and LG. Although the numerical concentration of fragments in TH was higher than in the Saigon River and NL, its mass concentration was smaller which can be explained by the scarcity of large fragments (Figure 7) as mass estimations were done based on surface measurements.

\section{Anthropogenic fibers versus fragments}

Globally, the concentrations of anthropogenic fibers were greater than those of fragments by 3-4 orders of magnitude (fibers: 172,000 to 519,000 items $\mathrm{m}^{-3}$; fragments: 10 to 223 items $\mathrm{m}^{-3}$ ). The mass concentrations were 1-3 orders of magnitude higher for fibers than for fragments (anthropogenic fibers: 4.72 to $220.63 \mathrm{mg} \mathrm{m}^{-3}$; fragments: 0.01 to $1.91 \mathrm{mg} \mathrm{m}^{-3}$ ). The greater surface and associated calculated volume of fragments may lead to a higher mass and consequently reduce the orders of magnitude from numerical to mass concentrations. Considering the mass estimation assumptions, their robustness can be questioned as mass concentrations can have a 2-fold variation depending on the assumption on fragments thickness and by one order of magnitude when fiber diameter is changed. Nonetheless, the assumptions regarding plastic density are based on actual polymer densities and even with variations of these densities, mass concentrations stay in the same range. In this river canal system, the total 
suspended matter concentrations are in the range of $30-140 \mathrm{mg} \mathrm{L}^{-1}$ (Strady et al., 2017). It is thus interesting to state that anthropogenic fiber mass concentrations and fragment mass concentrations represent roughly one per thousand and one per million of TSS mass concentrations, respectively.

\section{Conclusions}

The study of the tropical Saigon River canal system, crossing a developing South East Asian megacity, has highlighted high macroplastic and microplastic contamination. Land-based macroplastics entering the river, estimated between 0.96 and $19.91 \mathrm{~g}^{\text {inhabitant }} \mathrm{d}^{-1} \mathrm{~d}^{-1}$, seems to be related to local habits and waste management. The high concentrations of microplastics (fragments and anthropogenic fibers) in surface waters is related to the presence of several textile and plastics industries in the vicinity of HCMC as well as high macroplastic contamination and paucity of wastewater treatment in Vietnam. This data can thus serve waste management regulation agencies with their implementation of regulations on plastic litter and collection. This study, combining both macroplastic and microplastic assessments, has evidenced the close relationship between these two contaminants and the impact of macroplastic content on microplastic contamination via the assumed fragmentation and degradation throughout the size spectrum continuum. We therefore recommend that the link between these two size classes should not be overlooked in further studies. This study has also been the first to point out differences of microplastic contamination in the continental aquatic environments of high-income countries and lower middle-income countries. As plastic production is likely to increase over the next few years, macro- and microplastic contamination will remain an important concern: a better understanding of macro- and microplastic pollution, sources, variability and degradation processes is thus imperative. 


\section{Acknowledgments}

This study has been conducted under the framework of CARE-RESCIF initiative along with the Urban Development Management Support Centre of HCMC (PADDI) and the Department of Natural Resources and Environment of HCMC (DONRE). This study was funded by incentive grants from the French Research Institute of Sustainable Development (IRD). The PhD of Rachid Dris was funded by the region Île-de-France Research Network on Sustainable Development (R2DS Ile-de-France, Grant N²013-2). The authors thank Phan Thi San Ha, Joanne Aimé, Nguyen Truong An (CARE), Fanny Quertamp and Morgane Perset (PADDI) for their local support and help during sampling campaigns, and Anne Chabas (LISA, Laboratoire Interuniversitaire des Systèmes Atmosphériques) for technical support. The authors thank also the anonymous reviewers for their comments which improve the quality of the manuscript.

\section{References}

Allsopp, M., Walters, A., Santillo, D., and Johnston, P. (2006). Plastic debris in the world's oceans.

Arthur, C., Baker, J., and Bamford, H. (2009). Proceedings of the International Research Workshop on the Occurrence, Effects, and Fate of Microplastic Marine Debris, September 9$11,2008$.

Bakir, A., Rowland, S.J., and Thompson, R.C. (2012). Competitive sorption of persistent organic pollutants onto microplastics in the marine environment. Mar. Pollut. Bull. 64, 2782 2789.

Bakir, A., Rowland, S.J., and Thompson, R.C. (2014). Enhanced desorption of persistent organic pollutants from microplastics under simulated physiological conditions. Environ. Pollut. 185, 16-23.

Barnes, D.K.A., Galgani, F., Thompson, R.C., and Barlaz, M. (2009). Accumulation and fragmentation of plastic debris in global environments. Philos. Trans. R. Soc. B Biol. Sci. 364, 1985-1998.

Bejgarn, S., MacLeod, M., Bogdal, C., and Breitholtz, M. (2015). Toxicity of leachate from weathering plastics: An exploratory screening study with Nitocra spinipes. Chemosphere 132, $114-119$. 
Browne, M.A., Crump, P., Niven, S.J., Teuten, E., Tonkin, A., Galloway, T., and Thompson, R. (2011). Accumulation of Microplastic on Shorelines Woldwide: Sources and Sinks. Environ. Sci. Technol. 45, 9175-9179.

Carpenter, E.J., and Smith, K.L. (1972). Plastics on the Sargasso sea surface. Science 175, $1240-1241$.

Chae, Y., and An, Y.-J. (2017). Effects of micro- and nanoplastics on aquatic ecosystems: Current research trends and perspectives. Mar. Pollut. Bull.

Cooper, D.A., and Corcoran, P.L. (2010). Effects of mechanical and chemical processes on the degradation of plastic beach debris on the island of Kauai, Hawaii. Mar. Pollut. Bull. 60, $650-654$.

Derraik, J.G.. (2002). The pollution of the marine environment by plastic debris: a review. Mar. Pollut. Bull. 44, 842-852.

Di, W., and Wang, J., (2017). Microplastics in surface waters and sediments of the Three Gorges Reservoir, China. Sci. Tot. Environ. https://doi.org/10.1016/j.scitotenv.2017.10.150

Dris, R., Imhof, H., Sanchez, W., Gasperi, J., Galgani, F., Tassin, B., and Laforsch, C. (2015a). Beyond the ocean: Contamination of freshwater ecosystems with (micro-) plastic particles. Environ. Chem. 32.

Dris, R., Gasperi, J., Rocher, V., Saad, M., Renault, N., and Tassin, B. (2015b). Microplastic contamination in an urban area: a case study in Greater Paris. Environ. Chem.,pp2015.

Dris, R., Gasperi, J., Saad, M., Mirande, C., Tassin, B., 2016. Synthetic fibers in atmospheric fallout: a source of microplastics in the environment? Mar. Pollut.Bull. 104, 290-293.

Dris, R., Gasperi, J., Rocher V., Tassin, B., 2018. Synthetic and non-synthetic anthropogenic fibers in a river under the impact of Paris Megacity: Sampling methodological aspects and flux estimations. Sc. Tot. Environ., 618, 157-164.

Eerkes-Medrano, D., Thompson, R.C., and Aldridge, D.C. (2015). Microplastics in freshwater systems: A review of the emerging threats, identification of knowledge gaps and prioritisation of research needs. Water Res. 75, 63-82.

Estahbanati, S., and Fahrenfeld, N.L. (2016). Influence of wastewater treatment plant discharges on microplastic concentrations in surface water. Chemosphere 162, 277-284.

Expéditions MED (2016). Opération déchets côtiers.

FAO (2014). Aquastat: global information system on water and agriculture.

Faure, F., Demars, C., Wieser, O., Kunz, M., and De Alencastro, L.F. (2015). Plastic pollution in Swiss surface waters: Nature and concentrations, interaction with pollutants. Environ. Chem. 12, 582-591.

Gasperi, J., Dris, R., Bonin, T., Rocher, V., and Tassin, B. (2014). Assessment of floating plastic debris in surface water along the Seine River. Environ. Pollut. 195, 163-166. 
Givental, E. (2014). The Ho Chi Minh City canals: assessing vulnerability and resilience factors. Yearb. Assoc. Pac. Coast Geogr. 76, 49-67.

Hartline, N.L., Bruce, N.J., Karba, S.N., Ruff, E.O., Sonar, S.U., and Holden, P.A. (2016). Microfiber Masses Recovered from Conventional Machine Washing of New or Aged Garments. Environ. Sci. Technol. 50, 11532-11538.

Horton, A.A., Walton, A., Spurgeon, D.J., Lahive, E., and Svendsen, C. (2017). Microplastics in freshwater and terrestrial environments: Evaluating the current understanding to identify the knowledge gaps and future research priorities. Sci. Total Environ. 586, 127-141.

Jabeen, K., Su, L., Li, J., Yang, D., Tong, C., Mu, J., and Shi, H. (2017). Microplastics and mesoplastics in fish from coastal and fresh waters of China. Environ. Pollut. 221, 141-149.

Jambeck, J.R., Geyer, R., Wilcox, C., Siegler, T.R., Perryman, M., Andrady, A., Narayan, R., and Law, K.L. (2015). Plastic waste inputs from land into the ocean. Science 347, 768-771.

Jemec, A., Horvat, P., Kunej, U., Bele, M., and Kržan, A. (2016). Uptake and effects of microplastic textile fibers on freshwater crustacean Daphnia magna. Environ. Pollut. 219, 201-209.

JICA (2001). The Detailed Design Study on HCMC Water Environment Improvement Project - Chapter 3 Tau Hu - Ben Nghe canal improvement.

Kieu-Le, T.-C., Strady, E., and Perset, M. (2016). Life cycle of floating debris in the canals of Ho Chi Minh City (PADDI).

Le, T.M.T., Nguyen Phuoc, D., Dinh Quoc, T., Ngo, H.H., and Do Hong Lan, C. (2016). Presence of e-EDCs in surface water and effluents of pollution sources in Sai Gon and Dong Nai river basin. Sustain. Environ. Res. 26, 20-27.

Lebreton, L.C.M., van der Zwet, J., Damsteeg, J.-W., Slat, B., Andrady, A., and Reisser, J. (2017). River plastic emissions to the world's oceans. Nat. Commun. 8, 15611.

Leslie, H.A., Brandsma, S.H., van Velzen, M.J.M., and Vethaak, A.D. (2017). Microplastics en route: Field measurements in the Dutch river delta and Amsterdam canals, wastewater treatment plants, North Sea sediments and biota. Environ. Int. 101, 133-142.

Löder, M. and Gerdts, G., Methodology Used for the Detection and Identification of Microplastics-A Critical Appraisal, 2015. In: Marine Anthropogenic Litter, M. Bergmann, L. Gutow and M. Klages (editors) Marine Anthropogenic Litter, Berlin, Springer, 447 p., ISBN: 978-3-319-16510-3 . doi: 10.1007/978-3-319-16510-3 8

Magnusson, K., and Norén, F. (2014). Screening of microplastic particles in and down-stream a wastewater treatment plant (Swedish Environmental Research Institute: Stockholm, Sweden).

Mani, T., Hauk, A., Walter, U., and Burkhardt-Holm, P. (2015). Microplastics profile along the Rhine River. Sci. Rep. 5, 17988. 
Mason, S.A., Garneau, D., Sutton, R., Chu, Y., Ehmann, K., Barnes, J., Fink, P., Papazissimos, D., and Rogers, D.L. (2016). Microplastic pollution is widely detected in US municipal wastewater treatment plant effluent. Environ. Pollut. 218, 1045-1054.

Mato, Y., Isobe, T., Takada, H., Kanehiro, H., Ohtake, C., and Kaminuma, T. (2001). Plastic resin pellets as a transport medium for toxic chemicals in the marine environment. Environ. Sci. Technol. 35, 318-324.

Mintenig, S., Int-Veen, I., Löder, M., and Gerdts, G. (2014). Mikroplastik in ausgewählten Kläranlagen des Oldenburgisch - Ostfriesischen Wasserverbandes (OOWV) in Niedersachsen (Alfred-Wegener-Institut, Helmholtz-Zentrum für Polar-und Meeresforschung).

Morritt, D., Stefanoudis, P.V., Pearce, D., Crimmen, O.A., and Clark, P.F. (2014). Plastic in the Thames: A river runs through it. Mar. Pollut. Bull. 78, 196-200.

Napper, I.E., and Thompson, R.C. (2016). Release of synthetic microplastic plastic fibres from domestic washing machines: Effects of fabric type and washing conditions. Mar. Pollut. Bull. 112, 39-45.

Napper, I.E., Bakir, A., Rowland, S.J., and Thompson, R.C. (2015). Characterisation, quantity and sorptive properties of microplastics extracted from cosmetics. Mar. Pollut. Bull. 99, 178185.

Nguyen, T.V.H., Takizawa, S., Oguma, K., and Nguyen, V.P. (2011). Sources and leaching of manganese and iron in the Saigon River Basin, Vietnam. Water Sci. Technol. 63, 2231.

Peters, C.A., and Bratton, S.P. (2016). Urbanization is a major influence on microplastic ingestion by sunfish in the Brazos River Basin, Central Texas, USA. Environ. Pollut. 210, 380-387.

PlasticsEurope (2018). Plastics - the Facts 2017, An analysis of European latest plastics production, demand and waste data. Plast. Eur. Assoc. Plast. Manuf. Bruss.

Rehse, S., Kloas, W., and Zarfl, C. (2016). Short-term exposure with high concentrations of pristine microplastic particles leads to immobilisation of Daphnia magna. Chemosphere 153, 91-99.

Remy F., Collard F., Gilbert B., Compère P., Eppe G., Lepoint G. 2018. When Microplastic Is Not Plastic: The Ingestion of Artificial Cellulose Fibers by Macrofauna Living in Seagrass Macrophytodetritus. Environ. Sci. Technol., 2015, 49, pp 11158-11166.

Rochman, C.M., Tahir, A., Williams, S.L., Baxa, D.V., Lam, R., Miller, J.T., Teh, F.-C., Werorilangi, S., and Teh, S.J. (2015). Anthropogenic debris in seafood: Plastic debris and fibers from textiles in fish and bivalves sold for human consumption. Sci. Rep. 5.

Sadri, S.S., and Thompson, R.C. (2014). On the quantity and composition of floating plastic debris entering and leaving the Tamar Estuary, Southwest England. Mar. Pollut. Bull. 81, 5560 .

Sanchez, W., Bender, C., and Porcher, J.-M. (2014). Wild gudgeons (Gobio gobio) from French rivers are contaminated by microplastics: Preliminary study and first evidence. Environ. Res. 128, 98-100. 
Silva-Cavalcanti, J.S., Silva, J.D.B., França, E.J. de, Araújo, M.C.B. de, and Gusmão, F. (2017). Microplastics ingestion by a common tropical freshwater fishing resource. Environ. Pollut. 221, 218-226.

Steffen, W., Crutzen, P.J., and McNeill, J.R. (2007). The Anthropocene: Are Humans Now Overwhelming the Great Forces of Nature. AMBIO J. Hum. Environ. 36, 614-621.

Strady, E., Dang, V.B.H., Némery, J., Guédron, S., Dinh, Q.T., Denis, H., and Nguyen, P.D. (2017). Baseline seasonal investigation of nutrients and trace metals in surface waters and sediments along the Saigon River basin impacted by the megacity of Ho Chi Minh (Vietnam). Environ. Sci. Pollut. Res. 24, 3226-3243.

Talvitie, J., Heinonen, M., Paakkonen, J.-P., Vahtera, E., Mikola, A., Setala, O., and Vahala, R. (2015). Do wastewater treatment plants act as a potential point source of microplastics? Preliminary study in the coastal Gulf of Finland, Baltic Sea. Water Sci. Technol. 72, 14951504.

Textile Exchange, 2017. Preffered Fiber and material market report 2017. http://textileexchange.org/downloads/2017-preferred-fiber-materials-market-report/

Thao, V., and Godfrey, C. (2014). The resurrection of Nhieu Loc-Thi Nghe: How HCMC brought the black water canal back from the dead. Thanh Nien Dly.

Thompson, R.C., Moore, C.J., vom Saal, F.S., and Swan, S.H. (2009). Plastics, the environment and human health: current consensus and future trends. Philos. Trans. R. Soc. B Biol. Sci. 364, 2153-2166.

Turner, A., and Holmes, L.A. (2015). Adsorption of trace metals by microplastic pellets in fresh water. Environ. Chem. 12, 600-610.

VGP News (2017). Municipal Department of Planning and Investment, the online newspaper of the government of the Socialist Republic of Viet Nam. http://news.chinhphu.vn/

Vo, P.L. (2007). Urbanization and water management in Ho Chi Minh City, Vietnam-issues, challenges and perspectives. GeoJournal 70, 75-89.

Wagner, M., Scherer, C., Alvarez-Muñoz, D., Brennholt, N., Bourrain, X., Buchinger, S., Fries, E., Grosbois, C., Klasmeier, J., Marti, T., et al. (2014). Microplastics in freshwater ecosystems: what we know and what we need to know. Environ. Sci. Eur. 26, 1-9.

Wang, W., Ndungu, A.W., Li, Z., Wang, J., 2017. Microplastics pollution in inland freshwaters of China: A case study in urban surface waters of Wuhan, China. Sc. Tot. Environ. 575, 1369-1374.

Williams, A.T., and Simmons, S.L. (1996). The degradation of plastic litter in rivers: implications for beaches. J. Coast. Conserv. 2, 63-72.

World Bank (2012). Vietnam - Ho Chi Minh City Environmental Sanitation (Nhieu Loc-Thi Nghe Basin) Project (The World Bank). 
648 Zhang, K., Gong, W., Lv, J., Xiong, X., and Wu, C. (2015). Accumulation of floating

649 microplastics behind the Three Gorges Dam. Environ. Pollut. 204, 117-123.

650 Zhang, K., Xiong, X., Hu, H., Wu, C., Bi, Y., Wu, Y., Zhou, B., Lam, P.K.S., and Liu, J.

651 (2017). Occurrence and Characteristics of Microplastic Pollution in Xiangxi Bay of Three

652 Gorges Reservoir, China. Environ. Sci. Technol. 51, 3794-3801.

653 Zhao, S., Zhu, L., Wang, T., and Li, D. (2014). Suspended microplastics in the surface water 654 of the Yangtze Estuary System, China: First observations on occurrence, distribution. Mar. 655 Pollut. Bull. 86, 562-568.

656 Zhao, S., Zhu, L., and Li, D. (2015). Microplastic in three urban estuaries, China. Environ. 657 Pollut. 206, 597-604. 


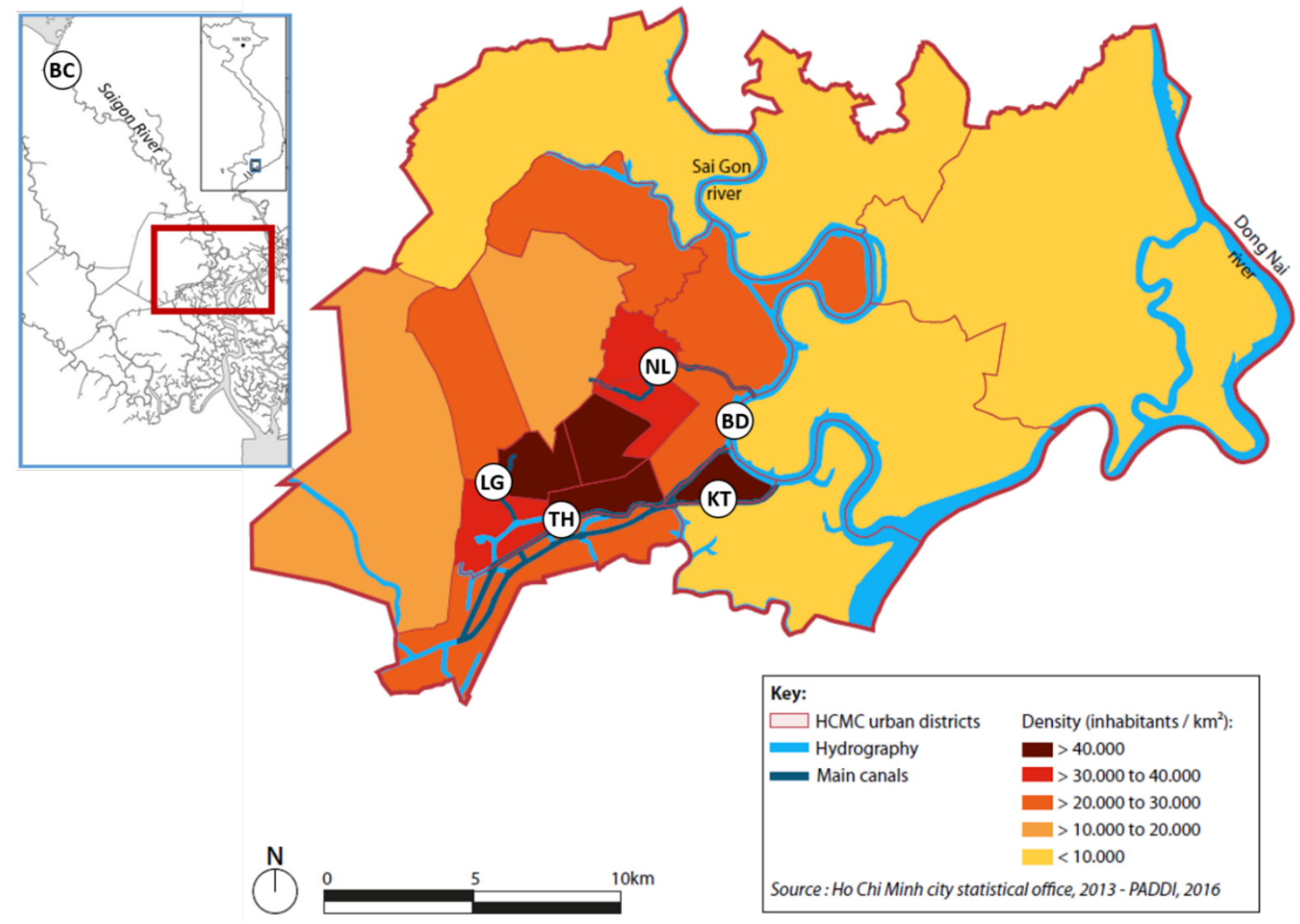

Figure 1: Map of the sampling sites. BC: Ben Cui, BD: Bach Dang, NL: Nhieu Loc - Thi Nghe, KT: Kenh Te, TH: Tau Hu, LG: Lo Gom. (adapted from Kieu-Le et al., 2016). 


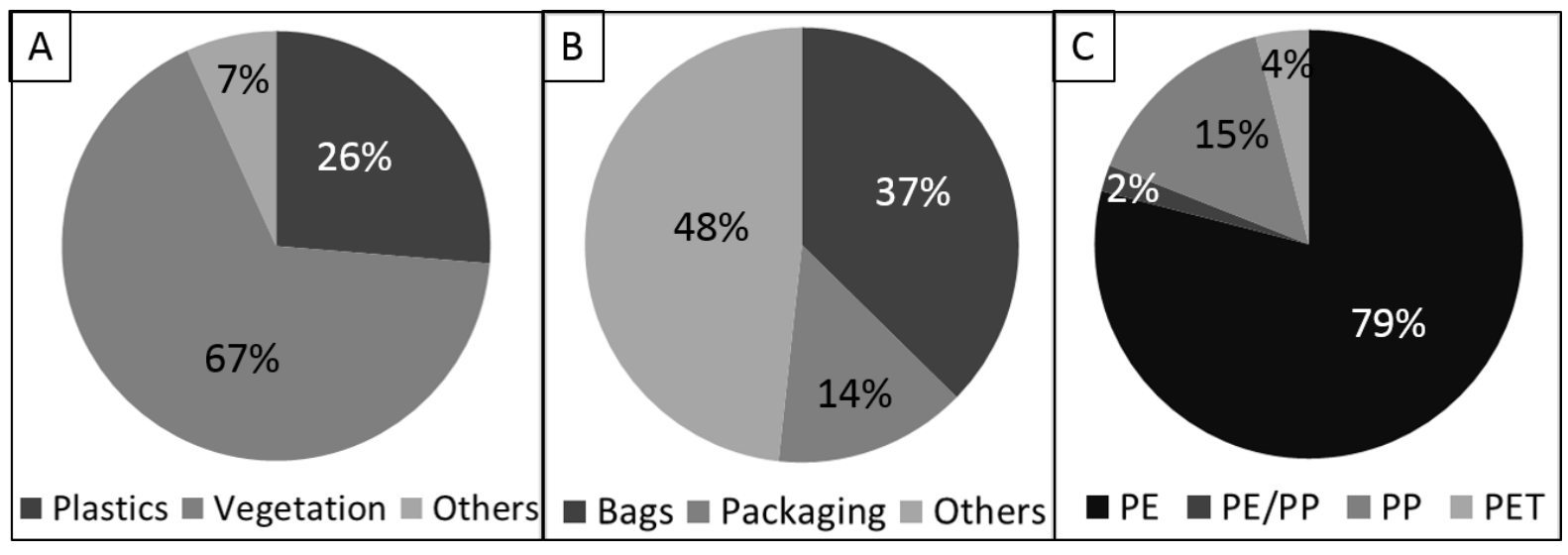

Figure 2: Macroplastic floating debris sort out and characterization at Nhieu Loc - Thi Nghe: A. Total floating debris sort out: plastic items, vegetation (water hyacinth, coconut), and others (shoes, mattress, wood furniture), B: Plastic debris sort out: plastic bags, plastic packaging (food take-out boxes, containers), and others (plastic bottles, food wrappings, cups, cutlery), C: Type of plastics for bBags and other plastics characterization: polypropylene (PP), polyethylene (PE), mix of PE and PP, and polyethylene terephthalate (PET). 


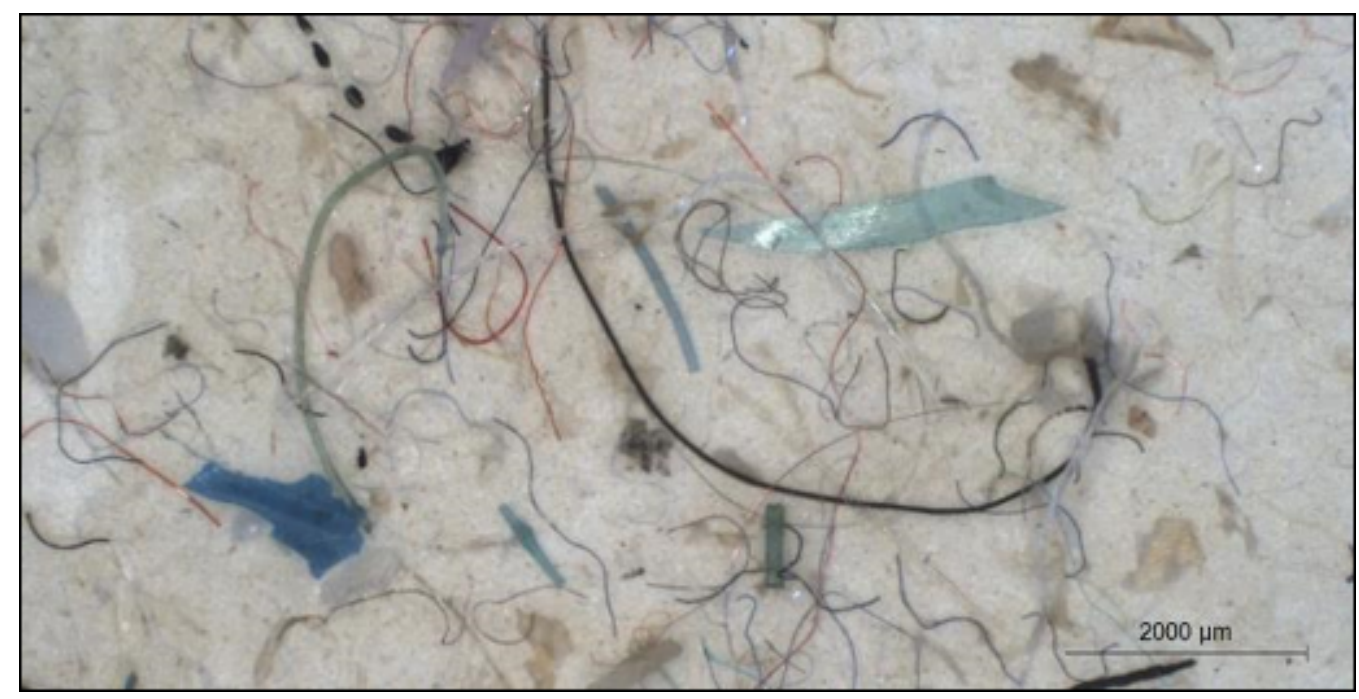

Figure 3: Stereomicroscope image of fibers and fragments collected in the Saigon River canal system on a GF/D filter. 


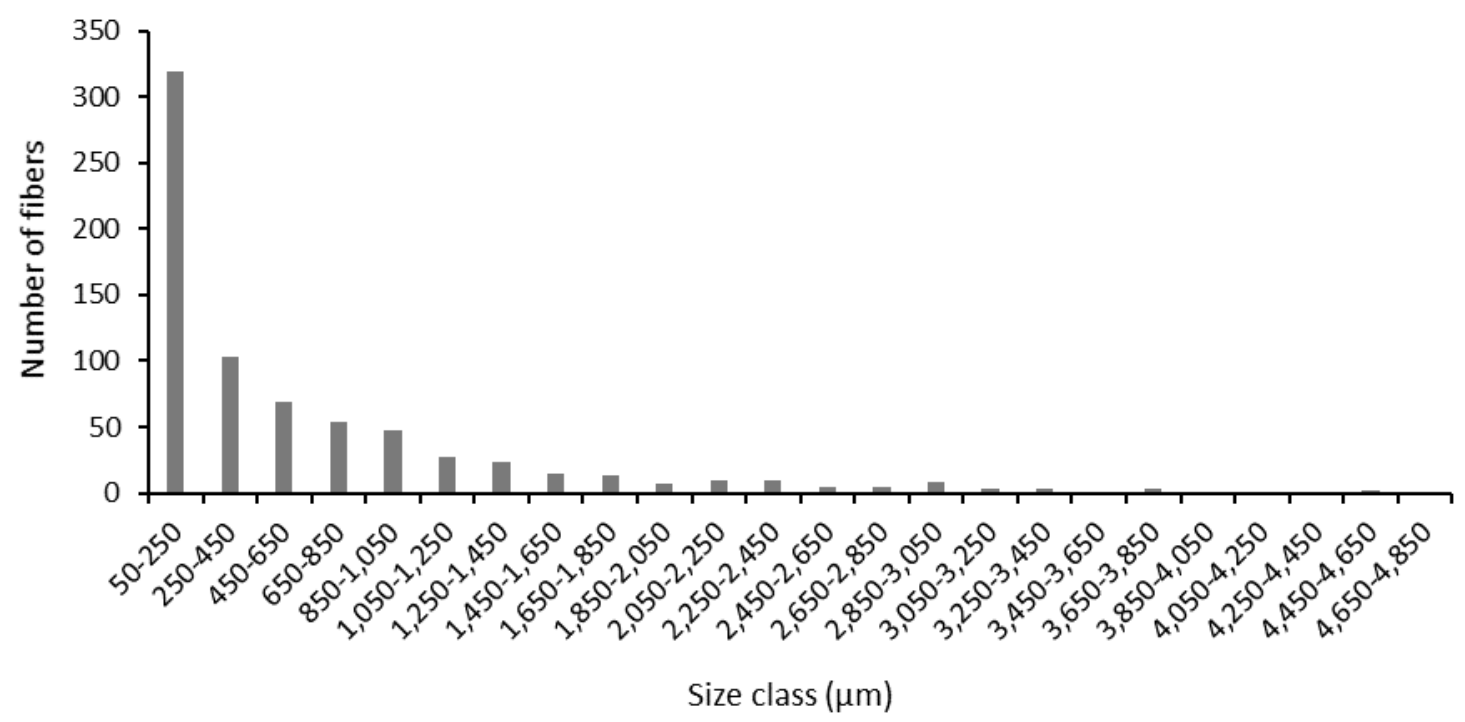

Figure 4: Cumulative anthropogenic fiber size distribution for all sites $(n=7)$. 


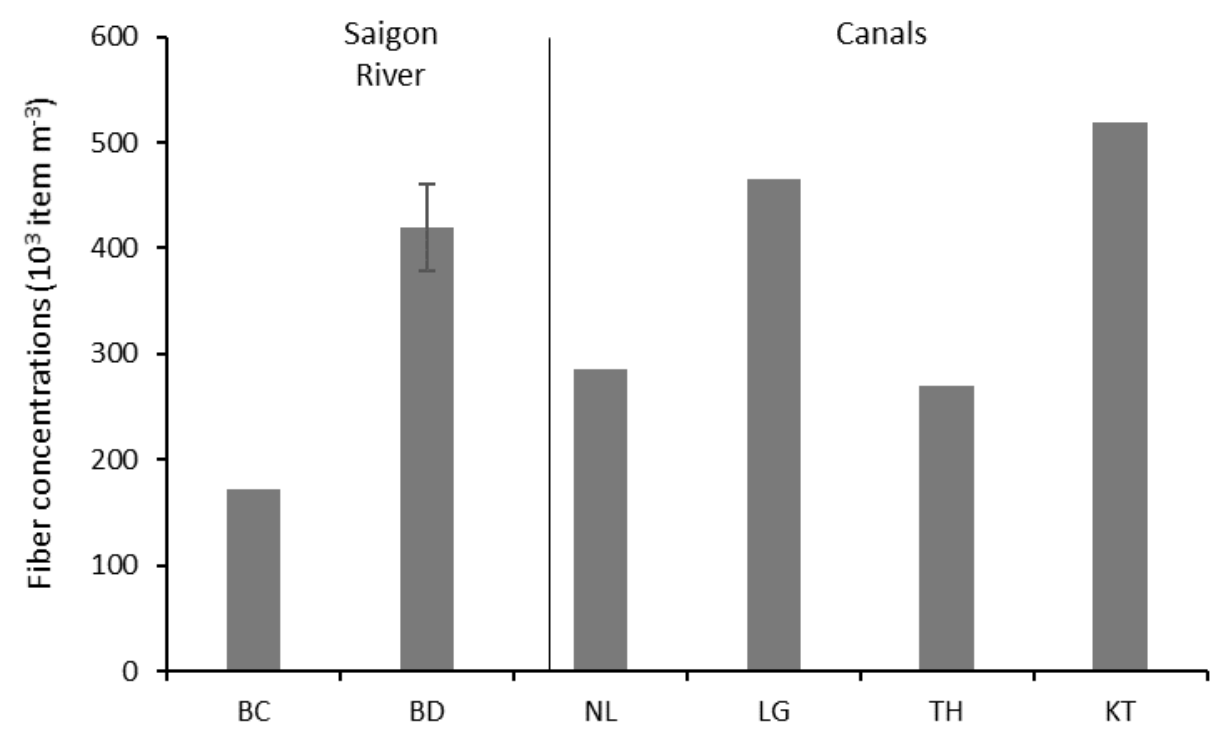

Figure 5: Anthropogenic fiber concentrations calculated in the Saigon River and canals $(\mathrm{n}=2$ for $\mathrm{BD})$. 


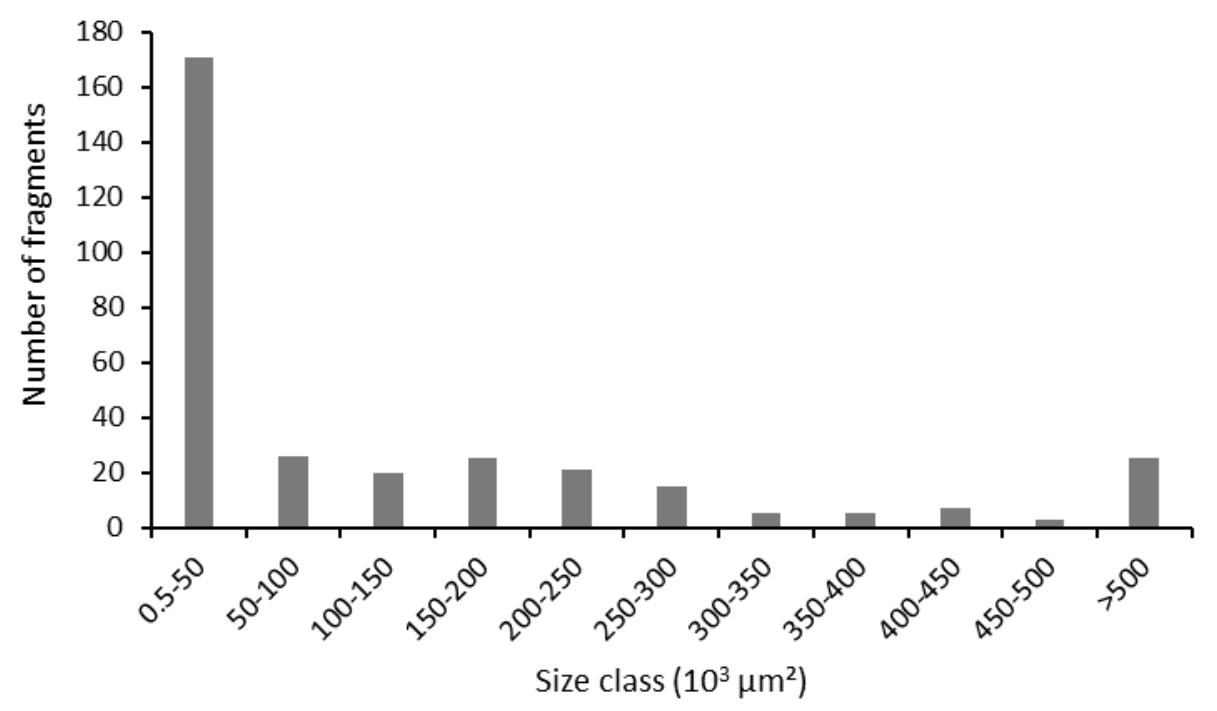

Figure 6: Cumulative fragment size distribution for all sampling sites $(n=6)$. 

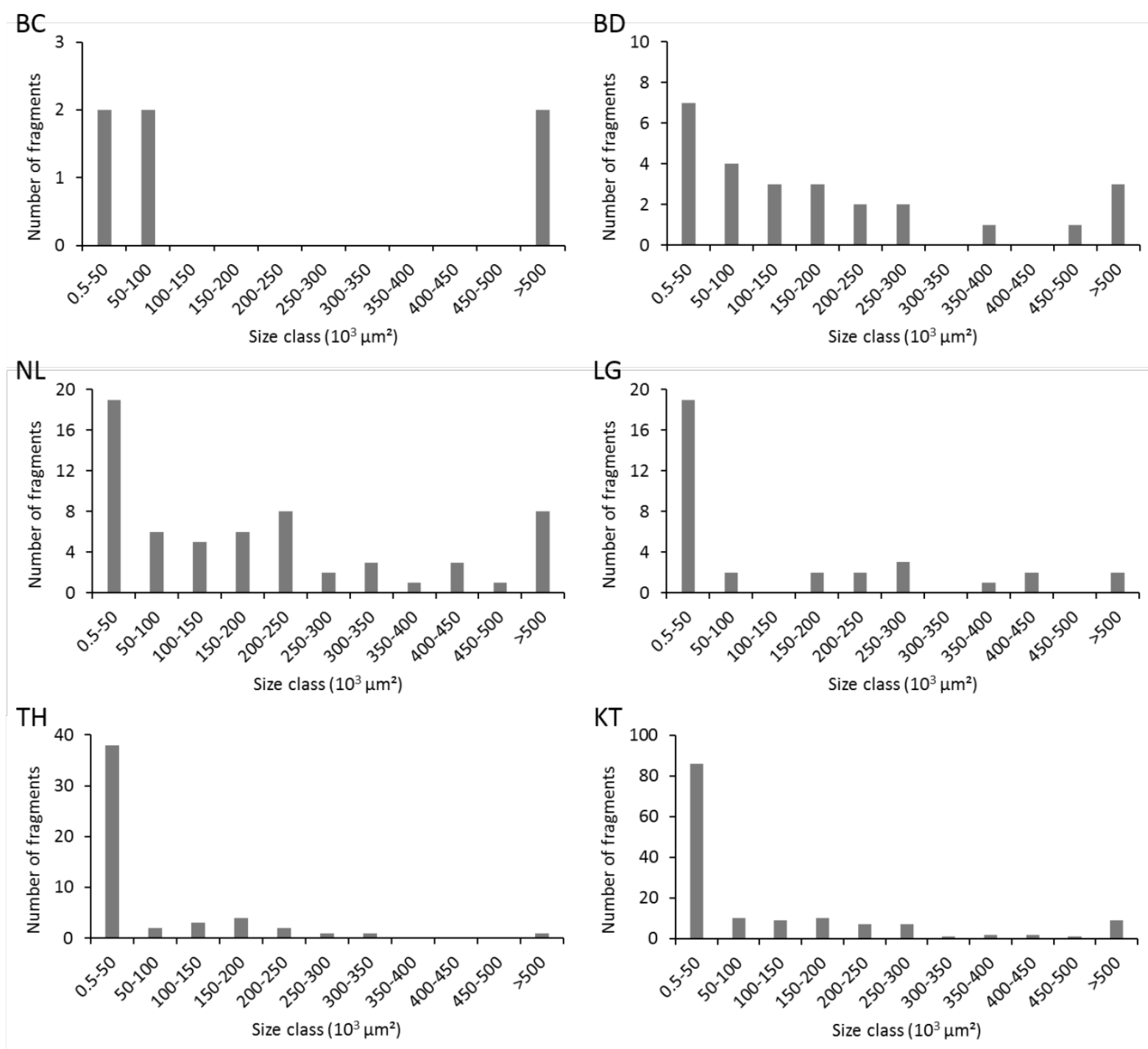

Figure 7: Fragment surface distribution at each site $(\mathrm{n}=6)$. 


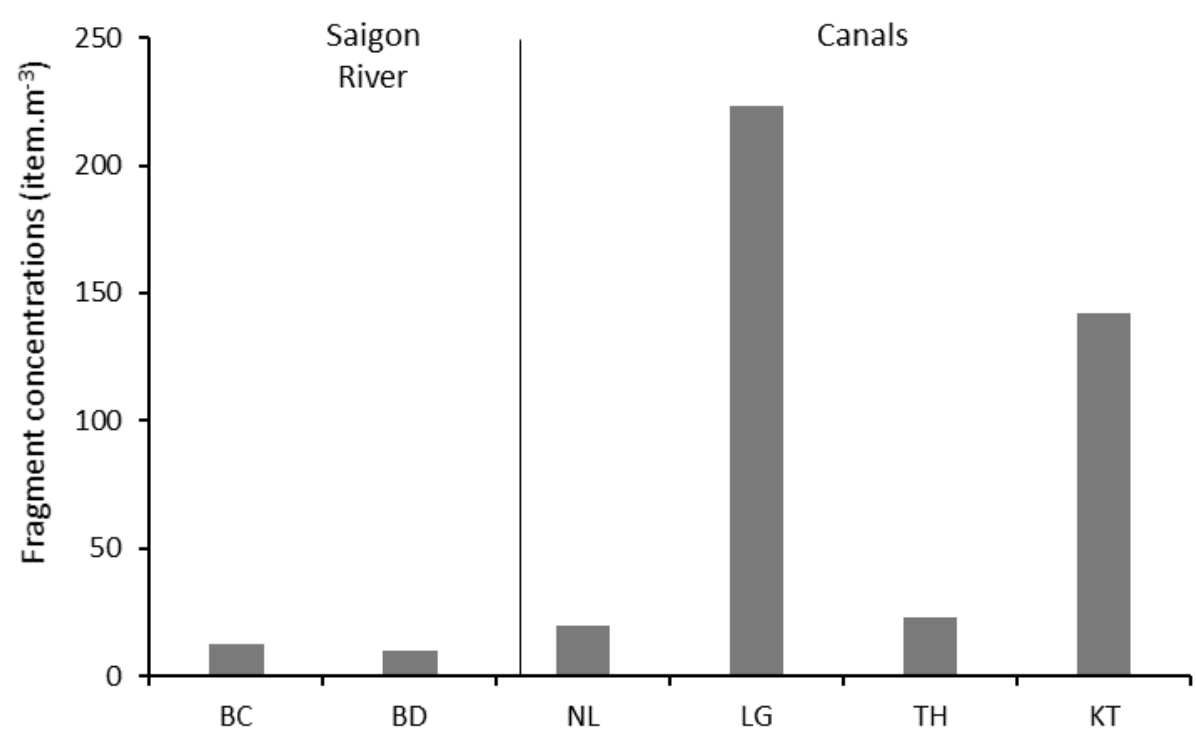

Figure 8: Fragment concentrations in the Saigon River and canals ( $\mathrm{n}=1$ for each site) 
Size class

Fibers $(\mu \mathrm{m})$

50-250

250-450

450-650

650-850

850-1,050

1,050-1,250

$1,250-1,450$

$1,450-1,650$

$1,650-1,850$

1,850-2,050

2,050-2,250

2,250-2,450

2,450-2,650

2,650-2,850

2,850-3,050

3,050-3,250

$3,250-3,450$

3,450-3,650

3,650-3,850

3,850-4,050

4,050-4,250

$4,250-4,450$

$4,450-4,650$

$4,650-4,850$

Fragments $\left(10^{3} \mu \mathrm{m}^{2}\right) \quad \mathrm{BC} \quad \mathrm{BD}$

0.5-50

50-100

100-150

150-200

200-250

250-300

300-350

350-400

400-450

450-500

$>500$

$\begin{array}{rrr}\mathrm{BC} & \mathrm{BD}(1) & \mathrm{BD}(2) \\ 20 & 100 & 93 \\ 8 & 7 & \\ 5 & 5 & \\ 2 & 1 & 6 \\ 6 & 6 & \\ 2 & 4 & \\ 3 & 1 & \\ 3 & 0 & \\ 0 & 0 & \\ 1 & 0 & \\ 0 & 2 & \\ 0 & 1 & \\ 0 & 1 & \\ 0 & 1 & 0 \\ 1 & 0 & 0 \\ 0 & 0 & 0 \\ 0 & 0 & 0 \\ 0 & 0 & 0 \\ 0 & 0 & 0 \\ 0 & 0 & 0 \\ 0 & 0 & 0 \\ 0 & 0 & 0 \\ 0 & 0 & 0 \\ 0 & 0 & 0\end{array}$

Sites

$\begin{array}{rrrrr}\text { NL } & \text { LG } & \text { TH } & \text { KT } & \text { Cumulative } \\ 27 & 30 & 13 & 36 & 319 \\ 20 & 23 & 14 & 29 & 103 \\ 8 & 19 & 11 & 19 & 69 \\ 10 & 13 & 5 & 17 & 54 \\ 7 & 7 & 8 & 9 & 48 \\ 1 & 4 & 4 & 7 & 27 \\ 3 & 10 & 3 & 3 & 23 \\ 2 & 4 & 2 & 2 & 14 \\ 1 & 5 & 3 & 3 & 13 \\ 0 & 2 & 3 & 1 & 7 \\ 0 & 5 & 0 & 2 & 10 \\ 0 & 3 & 4 & 2 & 10 \\ 0 & 2 & 0 & 1 & 4 \\ 0 & 1 & 0 & 2 & 4 \\ 0 & 4 & 0 & 3 & 8 \\ 1 & 1 & 0 & 1 & 3 \\ 0 & 1 & 0 & 2 & 3 \\ 0 & 1 & 0 & 0 & 1 \\ 0 & 0 & 2 & 1 & 3 \\ 0 & 0 & 0 & 0 & 0 \\ 0 & 0 & 0 & 0 & 0 \\ 0 & 0 & 0 & 0 & 0 \\ 1 & 0 & 1 & 0 & 2 \\ 0 & 0 & 0 & 0 & 0\end{array}$

$\begin{array}{rrrrr}\text { NL } & \text { LG } & \text { TH } & \text { KT } & \text { Cumulative } \\ 19 & 19 & 38 & 86 & 171 \\ 6 & 2 & 2 & 10 & 26 \\ 5 & 0 & 3 & 9 & 20 \\ 6 & 2 & 4 & 10 & 25 \\ 8 & 2 & 2 & 7 & 21 \\ 2 & 3 & 1 & 7 & 15 \\ 3 & 0 & 1 & 1 & 5 \\ 1 & 1 & 0 & 2 & 5 \\ 3 & 2 & 0 & 2 & 7 \\ 1 & 0 & 0 & 1 & 3 \\ 8 & 2 & 1 & 9 & 25\end{array}$

Table 1: Anthropogenic fiber and fragment size distribution for the six sites (two sampling at $\mathrm{BD})$. 


\section{Supporting information}

\section{Macro and microplastic contamination assessment of a tropical river (Saigon River, Vietnam) transversed by a developing megacity}

Lisa Lahens ${ }^{\mathrm{a}, \mathrm{c}}$, Emilie Strady ${ }^{\mathrm{b}, \mathrm{c}^{*}}$, Thuy-Chung Kieu-Le ${ }^{\mathrm{c}}$, Rachid Dris ${ }^{\mathrm{a}}$, Kada Boukermad, Emmanuel Rinnert ${ }^{d}$, Johnny Gasperi ${ }^{\mathrm{a}^{*}}$, Bruno Tassin ${ }^{\mathrm{a}^{*}}$

a. Université Paris-Est, LEESU, UMR MA 102 - AgroParisTech, 61 avenue du Général de Gaulle, 94010 Créteil Cedex, France

b. Univ. Grenoble Alpes, CNRS, IRD, Grenoble INP, IGE, F-38000 Grenoble, France

c. CARE, Ho Chi Minh City University of Technology, VNU-HCM, Viet Nam

d. Ifremer, LDCM, Centre Bretagne, ZI de la Pointe du Diable, CS 10070, 29280 Plouzané, France

*Corresponding authors: e-mail: emilie.strady@ird.fr, gasperi@u-pec.fr, bruno.tassin@enpc.fr 


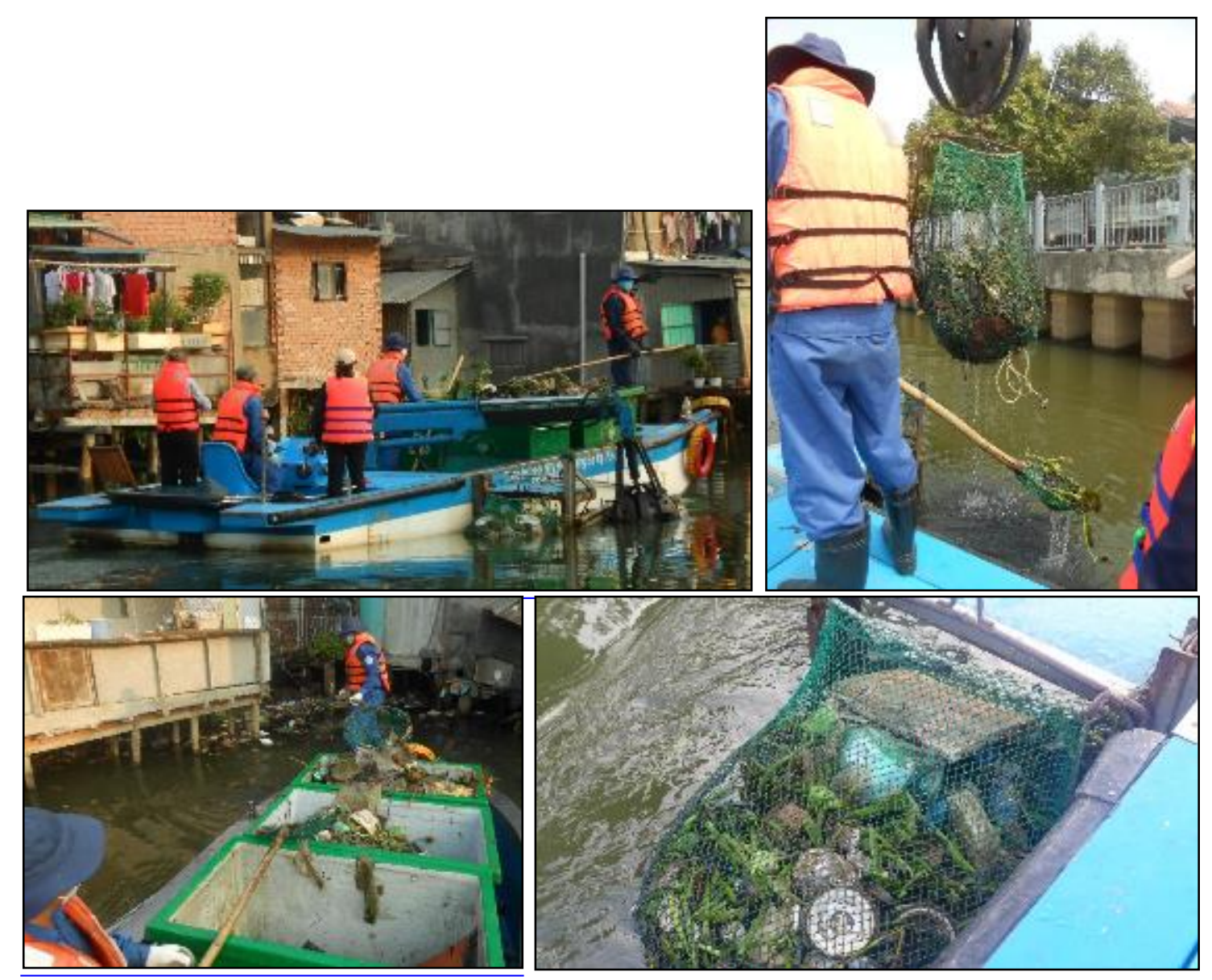

Figure S1: Pictures of debris collection on Nhieu Loc - Thi Nghe canal by the municipal company. 
Table S1: Estimations of the daily land-based macroplastic waste entering the river per inhabitant (g inhabitant ${ }^{-1}$ day $^{-1}$ ) on Nhieu Loc - Thi Nghe canal based on daily captured debris weight data. The estimations are based on four assumptions (refer to 2.2 Macroplastic assessment) relative to the daily captured debris weight, the efficiency of capture, the percentage of plastic items and the basin population.

\begin{tabular}{|c|c|c|c|c|c|c|}
\hline $\begin{array}{l}\text { Captured } \\
\text { debris } \\
\text { weight } \\
\text { (tons day-1) }\end{array}$ & $\begin{array}{c}\text { Capture } \\
\%\end{array}$ & $\begin{array}{c}\text { Canal } \\
\text { debris } \\
\text { weight } \\
\text { (tons day-1) }\end{array}$ & $\begin{array}{c}\text { Plastic } \\
\%\end{array}$ & $\begin{array}{c}\text { Plastic } \\
\text { weight } \\
\left(\text { tons day }^{-1}\right)\end{array}$ & $\begin{array}{c}\text { Basin } \\
\text { population } \\
\text { (inhabitants) }\end{array}$ & $\begin{array}{l}\text { land-based } \\
\text { macroplastic } \\
\text { waste entering } \\
\text { the river (g } \\
\text { inhabitant }^{-1} \\
\text { day }^{-1} \text { ) }\end{array}$ \\
\hline \multirow{12}{*}{10} & \multirow{6}{*}{100} & \multirow{6}{*}{10} & \multirow{2}{*}{11.5} & \multirow{2}{*}{1.15} & 1200000 & 0.96 \\
\hline & & & & & 522000 & 2.20 \\
\hline & & & \multirow{2}{*}{23.3} & \multirow{2}{*}{2.33} & 1200000 & 1.94 \\
\hline & & & & & 522000 & 4.46 \\
\hline & & & \multirow{2}{*}{43.3} & \multirow{2}{*}{4.33} & 1200000 & 3.61 \\
\hline & & & & & 522000 & 8.30 \\
\hline & \multirow{6}{*}{50} & \multirow{6}{*}{20} & \multirow{2}{*}{11.5} & \multirow{2}{*}{2.3} & 1200000 & 1.92 \\
\hline & & & & & 522000 & 4.41 \\
\hline & & & \multirow{2}{*}{23.3} & \multirow{2}{*}{4.66} & 1200000 & 3.88 \\
\hline & & & & & 522000 & 8.93 \\
\hline & & & \multirow{2}{*}{43.3} & \multirow{2}{*}{8.66} & 1200000 & 7.22 \\
\hline & & & & & 522000 & 16.59 \\
\hline \multirow{12}{*}{12} & \multirow{6}{*}{100} & \multirow{6}{*}{12} & \multirow{2}{*}{11.5} & \multirow{2}{*}{1.38} & 1200000 & 1.15 \\
\hline & & & & & 522000 & 2.64 \\
\hline & & & \multirow{2}{*}{23.3} & \multirow{2}{*}{2.796} & 1200000 & 2.33 \\
\hline & & & & & 522000 & 5.36 \\
\hline & & & \multirow{2}{*}{43.3} & \multirow{2}{*}{5.196} & 1200000 & 4.33 \\
\hline & & & & & 522000 & 9.95 \\
\hline & \multirow{6}{*}{50} & \multirow{6}{*}{24} & \multirow{2}{*}{11.5} & \multirow{2}{*}{2.76} & 1200000 & 2.30 \\
\hline & & & & & 522000 & 5.29 \\
\hline & & & \multirow{2}{*}{23.3} & \multirow{2}{*}{5.592} & 1200000 & 4.66 \\
\hline & & & & & 522000 & 10.71 \\
\hline & & & \multirow{2}{*}{43.3} & 10302 & 1200000 & 8.66 \\
\hline & & & & 10.392 & 522000 & 19.91 \\
\hline
\end{tabular}


Table S2: Estimations of fiber mass concentrations based on four assumptions relative to the minimum and maximum diameters of fibers $(\varphi: 8$ to $20 \mu \mathrm{m})$ and the minimum and maximum densities of polymer ( $\rho: 0.9$ to $1.4 \mathrm{~g} \mathrm{~cm}^{-3}$ ).

\begin{tabular}{|c|c|c|c|c|c|c|c|}
\hline \multirow[t]{4}{*}{ Site } & \multirow{4}{*}{$\begin{array}{l}\text { Sample } \\
\text { volume } \\
\left(\mathrm{m}^{3}\right)\end{array}$} & \multirow{4}{*}{$\begin{array}{c}\text { Cumulative } \\
\text { length } \\
(\mu \mathrm{m})\end{array}$} & \multicolumn{5}{|c|}{ Fibers mass concentrations (mg. $\left.\mathrm{m}^{-3}\right)$} \\
\hline & & & $\begin{array}{l}\min \varphi- \\
\min \rho\end{array}$ & $\begin{array}{l}\min \varphi- \\
\max \rho\end{array}$ & $\begin{array}{l}\max \varphi- \\
\min \rho\end{array}$ & $\begin{array}{l}\max \varphi- \\
\max \rho\end{array}$ & Median \\
\hline & & & 8 & 8 & 20 & 20 & \\
\hline & & & 0.9 & 1.4 & 0.9 & 1.4 & \\
\hline $\mathrm{BC}$ & $2.96 \times 10^{-4}$ & $3.12 \times 10^{4}$ & 4.76 & 7.41 & 29.78 & 46.32 & 18.60 \\
\hline $\mathrm{BD}(1)$ & $2.90 \times 10^{-4}$ & $4.00 \times 10^{4}$ & 6.23 & 9.70 & 38.96 & 60.61 & 24.33 \\
\hline $\mathrm{BD}(2)$ & $3.00 \times 10^{-4}$ & $3.13 \times 10^{4}$ & 4.72 & 7.35 & 29.52 & 45.92 & 18.43 \\
\hline NL & $2.84 \times 10^{-4}$ & $4.54 \times 10^{4}$ & 7.24 & 11.26 & 45.25 & 70.394 & 28.26 \\
\hline LG & $2.90 \times 10^{-4}$ & $1.39 \times 10^{5}$ & 21.62 & 33.63 & 135.13 & 210.20 & 84.38 \\
\hline $\mathrm{TH}$ & $2.70 \times 10^{-4}$ & $6.74 \times 10^{4}$ & 11.30 & 17.57 & 70.60 & 109.82 & 44.08 \\
\hline $\mathrm{KT}$ & $2.70 \times 10^{-4}$ & $1.35 \times 10^{5}$ & 22.69 & 35.30 & 142.83 & 220.63 & 88.57 \\
\hline
\end{tabular}

Table S3: Estimations of fragment mass concentrations based on four assumptions relative to the minimum and maximum surfaces of fragments ( $\mu$ : 10 to $\left.40 \mu \mathrm{m}^{2}\right)$ and the minimum and maximum densities of polymer ( $\rho: 0.9$ to $\left.1.6 \mathrm{~g} \mathrm{~cm}^{-3}\right)$.

\begin{tabular}{|c|c|c|c|c|c|c|c|}
\hline \multirow[t]{4}{*}{ Site } & \multirow{4}{*}{$\begin{array}{l}\text { Sample } \\
\text { volume } \\
\left(\mathrm{m}^{3}\right)\end{array}$} & \multirow{4}{*}{$\begin{array}{c}\text { Cumulative } \\
\text { surface } \\
\left(\mu \mathrm{m}^{2}\right)\end{array}$} & \multicolumn{5}{|c|}{ Fragments mass concentrations $\left(\mathrm{mg} \cdot \mathrm{m}^{-3}\right)$} \\
\hline & & & $\begin{array}{l}\min \mu- \\
\min \rho\end{array}$ & $\begin{array}{l}\min \mu- \\
\max \rho\end{array}$ & $\begin{array}{l}\max \mu- \\
\min \rho\end{array}$ & $\begin{array}{l}\max \mu- \\
\max \rho\end{array}$ & Median \\
\hline & & & 10 & 10 & 40 & 40 & \\
\hline & & & 0.9 & 1.6 & 0.9 & 1.6 & \\
\hline $\mathrm{BC}$ & 0.47 & $2.0 \times 10^{6}$ & 0.04 & 0.06 & 0.15 & 0.24 & 0.11 \\
\hline $\mathrm{BD}$ & 2.69 & $6.6 \times 10^{6}$ & 0.02 & 0.03 & 0.09 & 0.14 & 0.06 \\
\hline NL & 3.18 & $1.8 \times 10^{7}$ & 0.05 & 0.08 & 0.20 & 0.32 & 0.14 \\
\hline LG & 0.15 & $5.0 \times 10^{6}$ & 0.31 & 0.48 & 1.23 & 1.91 & 0.85 \\
\hline TH & 2.28 & $3.1 \times 10^{6}$ & 0.01 & 0.02 & 0.05 & 0.08 & 0.03 \\
\hline KT & 1.01 & $1.8 \times 10^{7}$ & 0.16 & 0.26 & 0.66 & 1.02 & 0.46 \\
\hline
\end{tabular}

